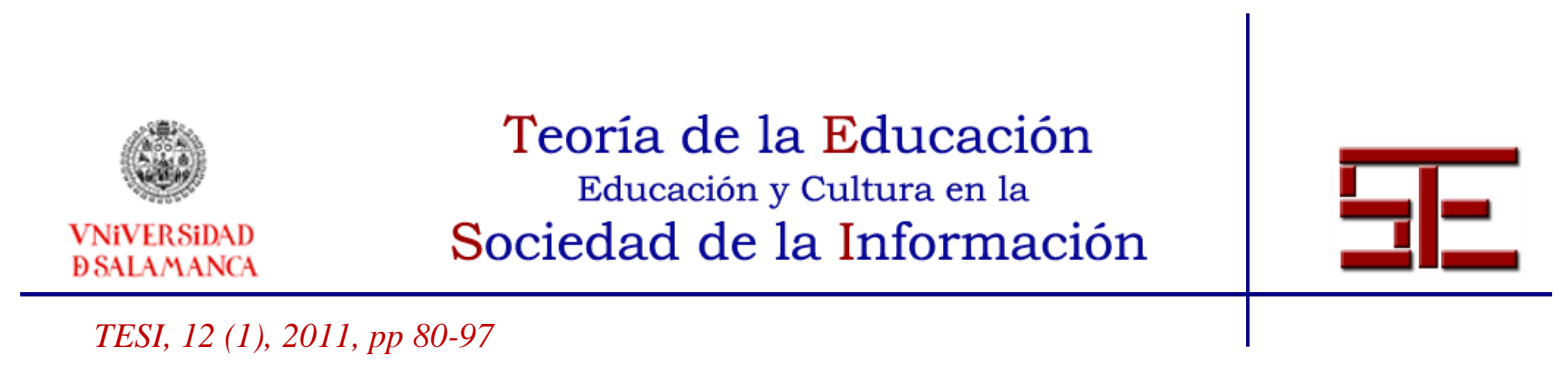

\title{
SEMÁNTICA DE LAS BÚSQUEDAS DE INFORMACIÓN EN ENTORNOS VIRTUALES DE FORMACIÓN
}

Resumen: El proceso de búsqueda de información situada en Internet, específicamente con propósitos formativos, ha generado preocupación en los profesores, ya que mucha de esa información, que está disponible y es de fácil acceso, no está validada ni es suministrada por entes confiables, por lo que los estudiantes pueden estar basando su aprendizaje en información que no es correcta. La colaboración de los ordenadores en este proceso puede asumir una parte de la carga intelectual del tratamiento de la información, apoyando los procesos cognitivos, realizando operaciones menores de automatización y clasificación de los resultados, previas a la evaluación por parte del estudiante. Nuestra investigación se basa en esto, por lo que propone incorporar un componente semántico, asociado al significado que representan los objetos y recursos que se encuentran en el entorno virtual de formación, con la intención de que reflejen relaciones semánticas entre el conocimiento previo de los estudiantes y la información encontrada en sus procesos de búsqueda, permitiéndoles identificar cuándo un material representa un aporte válido y cuándo se aleja de su objetivo.

Palabras clave: búsquedas en Internet; semántica; entornos virtuales de formación.

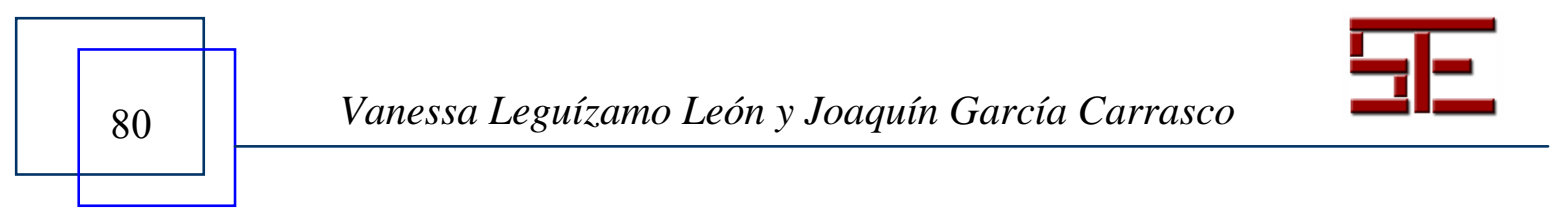




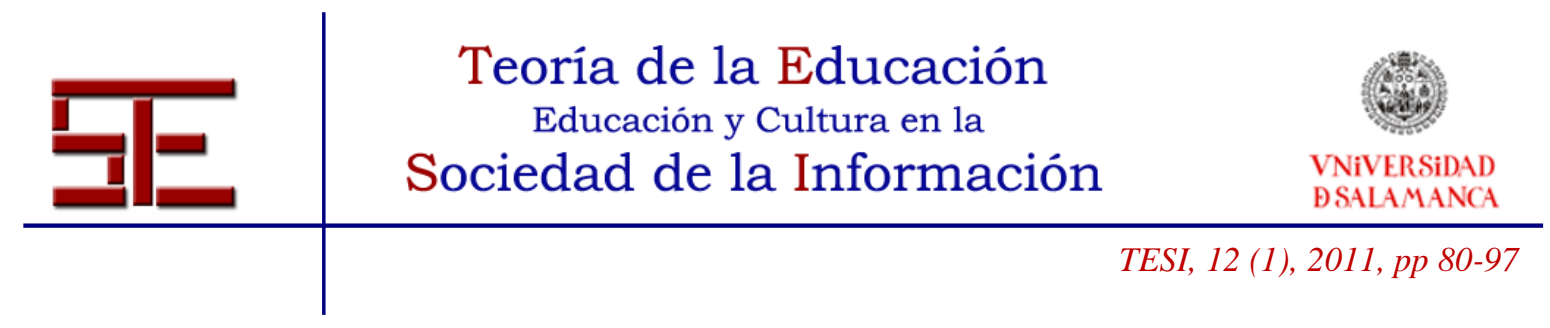

\title{
SEMANTICS OF THE INFORMATION SEARCHES IN VIRTUAL LEARNING ENVIRONMENTS
}

\begin{abstract}
The situated search process on the Internet with educational purposes has generated some preoccupation to the teachers, because much of the information that is available and easy access is not validate, or provided by trusted entities, so the students may be basing their learning with information that is incorrect. The collaboration of computers in this process assumes a part of the intellectual load of information processing, supported the cognitive process when perform automated minor operations and sorting results, before assessment by the student. This is the basis of our research. We propose to incorporate a semantic component, associated with the meaning that representing the objects and resources of the virtual learning environment, with the intention that these objects reflect the semantic relationships between student se $^{\text {eq }}$ prior knowledge and the information found in their search process, enabling them to identify when a material is a valid contribution in their learning process or when these material is away from your goal.
\end{abstract}

Keywords: Internet search; semantics; virtual learning environments.

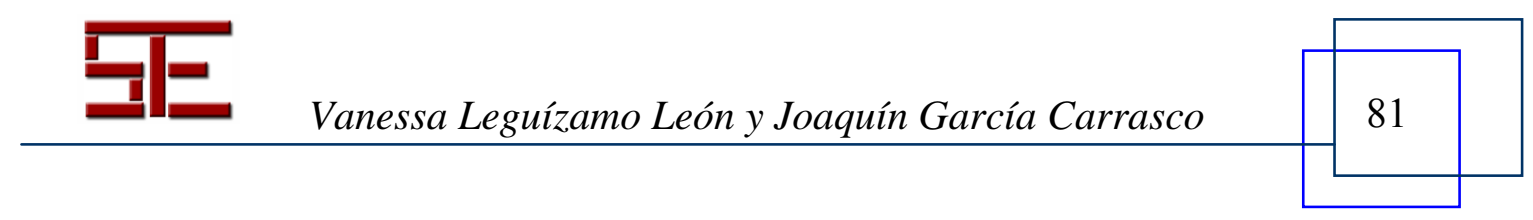




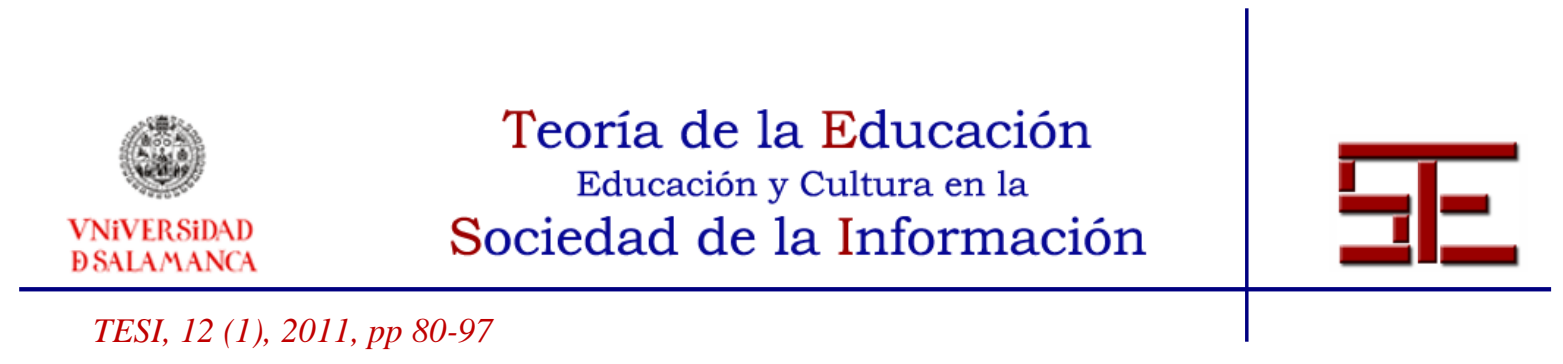

\section{SEMÁNTICA DE LAS BÚSQUEDAS DE INFORMACIÓN EN ENTORNOS VIRTUALES DE FORMACIÓN}

Fecha de recepción: 12/10/2010; fecha de aceptación: 15/01/2011; fecha de publicación: 31/03/2011

Vanessa Leguízamo León

vanessa.leguizamo@,ciens.ucv.ve

Universidad Central de Venezuela

Joaquín García Carrasco

carrasco@usal.es

Universidad de Salamanca

\section{1.- INTRODUCCIÓN}

En cualquier proceso educativo que se lleve a cabo, existe una lucha constante por la búsqueda de información que robustezca ese proceso, y permita al estudiante hacerse con nuevos conocimientos producto de la información que ha conseguido. Cuando nos situamos en un contexto tecnológico, observamos que la cantidad de información que se encuentra disponible y de fácil acceso es inimaginable, y la mayoría de las veces también inmanejable, dada la variedad de materiales que es posible obtener de la Red. Este proceso de búsqueda situada, en Internet, con propósitos formativos ha generado cierta preocupación en los profesores, ya que mucha de la información que se consigue en Internet no está validada ni es suministrada por entes confiables, por lo que los estudiantes pueden estar basando su aprendizaje en información incorrecta. El motivo de nuestra investigación se basa en esto último, por lo que hemos considerado que una manera de canalizar esas búsquedas parte de incorporar un componente semántico, dentro de los espacios virtuales de formación que sirven como punto de partida en el proceso de aprendizaje de los estudiantes. Este componente semántico está asociado a los objetos y recursos que se encuentran en el entorno virtual de formación. Estos elementos deben tener la capacidad de reflejar relaciones semánticas entre el conocimiento previo de los estudiantes y la información encontrada en sus procesos de búsqueda, permitiéndoles, con esta ayuda, identificar cuándo un material representa un aporte válido en su proceso formativo y cuándo se aleja de su objetivo.

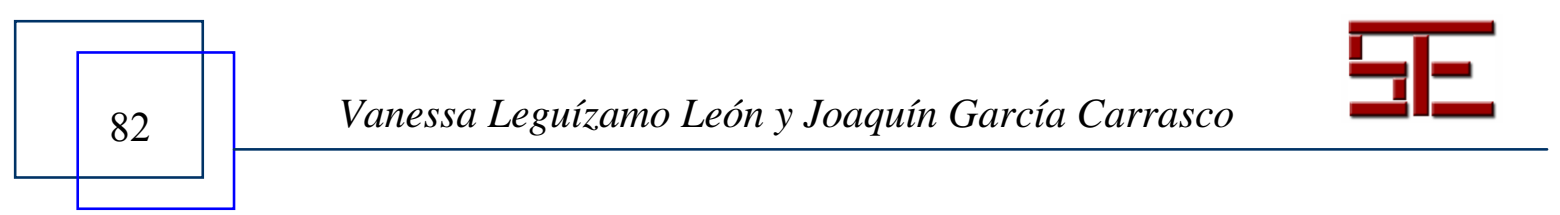




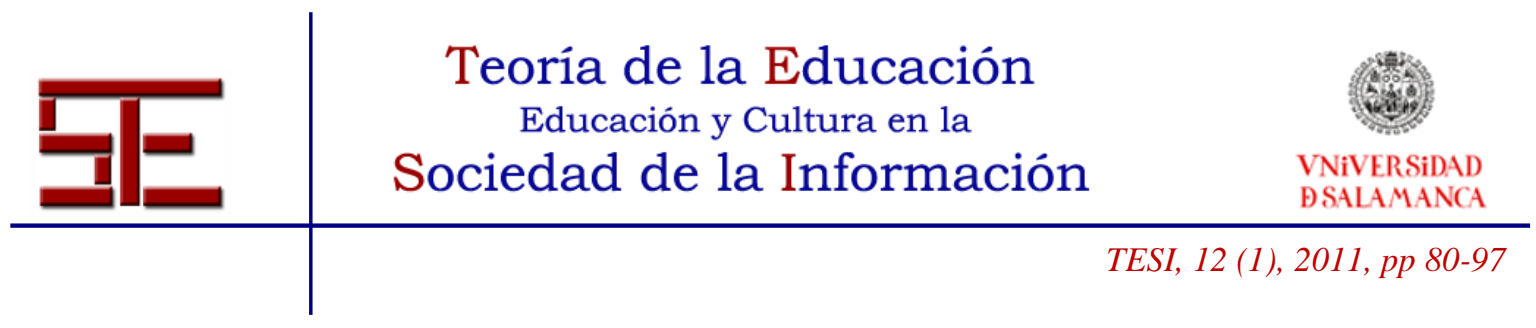

\section{2.- BÚSQUEDAS TEXTUALES EN INTERNET}

Internet se ha convertido en una gran red de recursos de diferentes naturalezas, tanto es así, que es posible encontrar información de casi cualquier tipo, en cualquier ámbito o contexto. Esta característica tiene un gran potencial, en cuanto es posible obtener mucha información, que está disponible de manera gratuita y que puede ser utilizada inmediatamente.

No existe un ente regulador de los contenidos que se colocan en Internet, por lo que es difícil determinar la procedencia, fiabilidad y validez de la información allí encontrada. El problema comienza al buscar información en un contexto particular, ya que es necesario contar con aplicaciones que realicen búsquedas sobre esa gran masa de información desordenada que constituye Internet. Para ello, existen buscadores que facilitan esta actividad, realizando búsquedas sobre una parte considerable de estos recursos.

Estas búsquedas son realizadas por los buscadores a través de palabras clave que son suministradas por los usuarios. Con estas palabras, el buscador realiza una búsqueda textual sobre los recursos presentes en Internet, esto es, busca las palabras indicadas por los usuarios sobre los materiales disponibles en la Red. Por ejemplo, supongamos que se quiere buscar información de la historia de la informática en Internet, y para ello se selecciona el buscador Google para realizarla. Se indica al buscador las palabras que corresponden a la búsqueda deseada, y Google devolverá como resultado aproximadamente 1.650 .000 páginas web, que contienen la frase historia de la informática, pero también aquellas que tengan sólo la palabra historia o sólo la palabra informática. Dentro de estos resultados es posible conseguir páginas web de historia universal, historia del arte, ingeniería informática, cursos de informática, entre otras muchas donde aparezca cualquiera de las palabras clave. Esta búsqueda puede ser restringida, utilizando comillas dobles (" ") para delimitar la frase, en este caso Google sólo retornará páginas web donde se encuentre la frase completa historia de la informática. Al realizar esta búsqueda, Google consigue aproximadamente 48.400 resultados donde es posible conseguir páginas web que contengan información de la historia de la informática, pero también aquellas que hagan referencia a la historia de la informática, pero no la desarrollen como tal, o incluso páginas web de cursos donde la historia de la informática sea un tópico a tratar. En cualquiera de los dos casos, la cantidad de información encontrada es inmanejable (1.650.000 y 48.400 resultados), y la única manera de determinar si la información es útil o no es visitando cada una de las páginas web encontradas. Así como la cantidad de información crece continuamente en

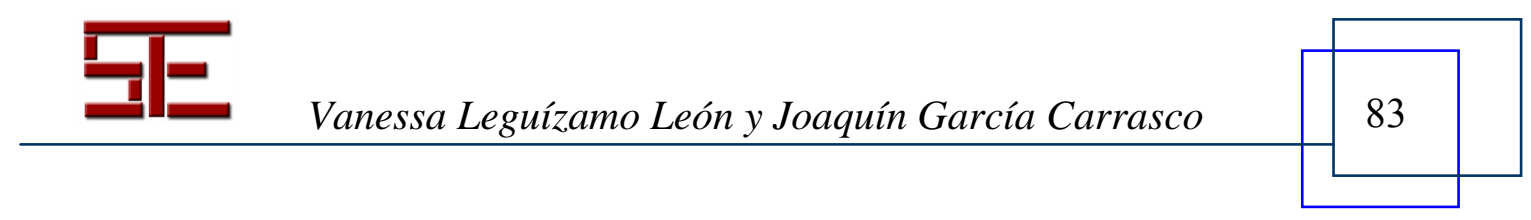




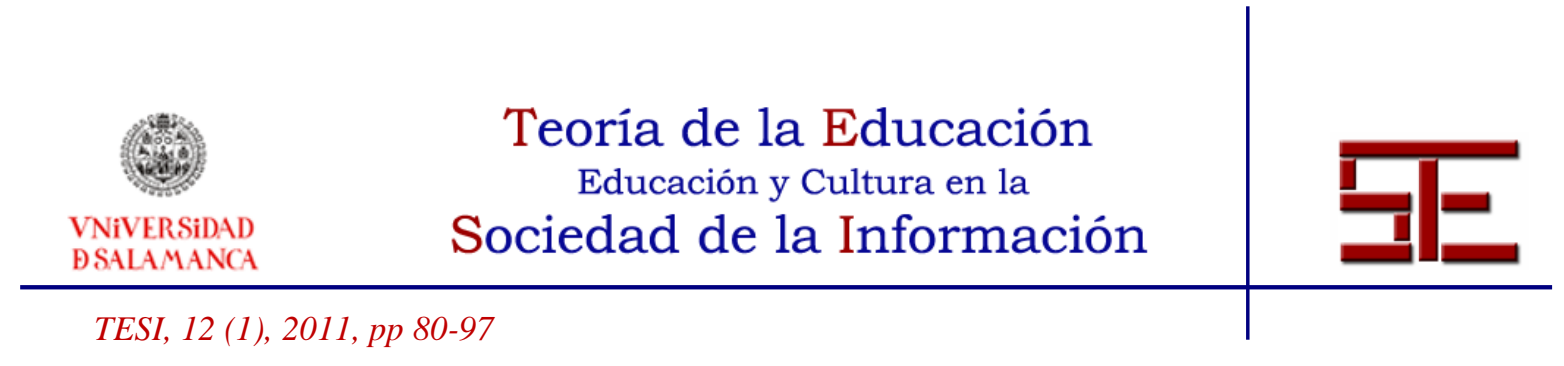

Internet, también tiende a ser volátil, por lo que es posible que al repetir una búsqueda un tiempo después, se obtenga un resultado parcial o totalmente distinto.

Por otra parte, dependiendo de la habilidad que tenga el usuario para realizar búsquedas sobre Internet, es probable que obtenga gran cantidad de resultados, y que la búsqueda manual sobre ellos incluso llegue a ser frustrante. En este caso, manejar la gran cantidad de información obtenida puede ser un proceso complejo, más aún si el usuario debe determinar por sí mismo cuál es válida y cuál no lo es. Con la intención de solucionar en parte estos problemas, surge la tecnología de web Semántica, que se define a continuación.

\section{3.- WEB SEMÁNTICA}

En el año 2001, Tim Berners-Lee, junto con James Hendler, publicaron un artículo en la revista Nature, donde exponen que la Web fue diseñada como un espacio de información, no sólo entre humanos, sino también donde pudieran participar los ordenadores con el fin de ayudar a los humanos a conseguir sus objetivos en la Red. El mayor obstáculo para que los ordenadores puedan participar ayudando a los usuarios es que la información que se consigue en Internet esté construida realmente para consumo humano; pero no se encuentra estructurada, los datos que allí se contienen no están bien diseñados como para poder ser manipulados por un ordenador (Berners-Lee \& Hendler, 2001). Los autores de este trabajo proponen la incorporación de una nueva tecnología a los documentos que se colocan en la Red, que permita a los usuarios crearlos para que estos puedan ser procesados de manera eficiente por los ordenadores, ser encontrados con mayor rapidez y con mayor porcentaje de acierto. Esta tecnología es lo que se denomina Web Semántica.

La Web Semántica es una Web extendida, dotada de mayor significado, en la que cualquier usuario en Internet podrá encontrar respuestas a sus preguntas de forma más rápida y sencilla gracias a una información mejor definida. Al dotar a la Web de más significado y, por lo tanto, de mayor relevancia semántica, se pueden obtener soluciones a problemas habituales en la búsqueda de información, gracias a la utilización de una infraestructura común, mediante la cual, es posible compartir, procesar y transferir información relevante de manera sencilla. Esta Web extendida y basada en el significado, se apoya en lenguajes universales que resuelven los problemas ocasionados por una Web carente de semántica en la que, en ocasiones, el acceso a la información se convierte en una tarea difícil y frustrante (World Wide Web Consortium W3C, 2006).

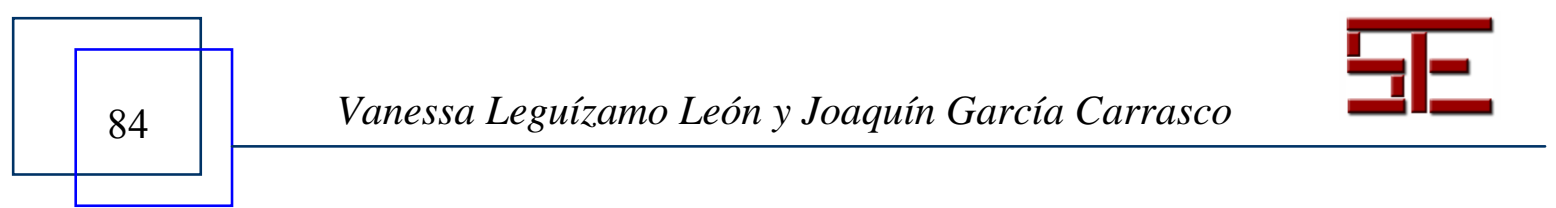




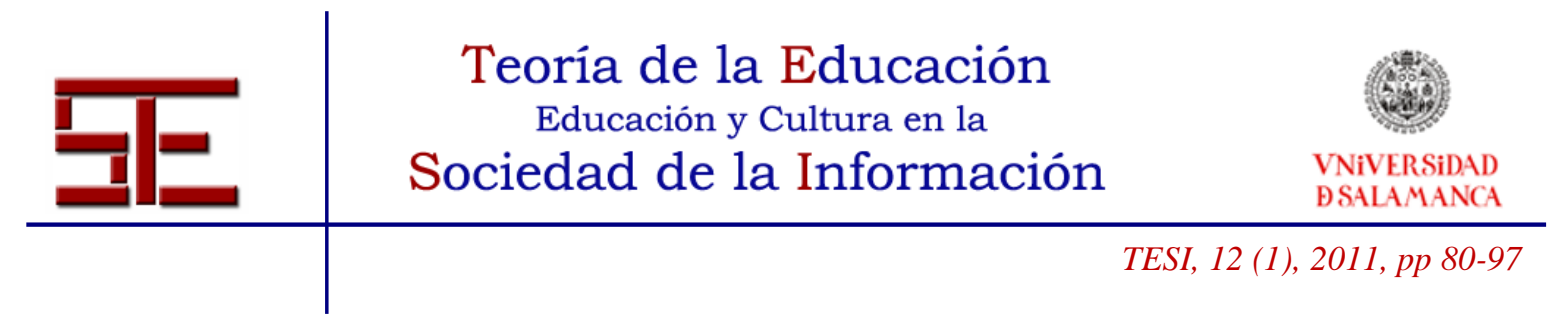

\section{1.- Funcionamiento de la Web Semántica}

La Web Semántica parte del principio de ubicar con precisión cualquier recurso que se encuentre en la Red. Para ello utiliza las URI's (Uniform Resource Identifier) que permiten identificar unívocamente un recurso en la Red, el subconjunto más conocido de ellas son los URL ${ }^{c e}$ (Uniform Resource Locator). Así, podemos acceder a cualquier página web con una dirección o URL que la referencia, por ejemplo, la dirección http://www.ucv.ve referencia a la página web de la Universidad Central de Venezuela, y sólo a esa página. Independientemente del lugar o del navegador que utilicemos para acceder a ella, al colocar esa dirección, el navegador nos llevará a esa página web y no a otra.

El modelo de datos que describirá los recursos contenidos en la Web Semántica se basa en la idea de convertir las declaraciones de los recursos en expresiones con la forma sujeto-predicado-objeto (conocidas como tripletes). El sujeto es el recurso, es decir, aquello que se está describiendo. El predicado es la propiedad o relación que se desea establecer acerca del recurso. Por último, el objeto es el valor de la propiedad o el otro recurso con el que se establece la relación. En la Figura 1 se muestra gráficamente esta relación.

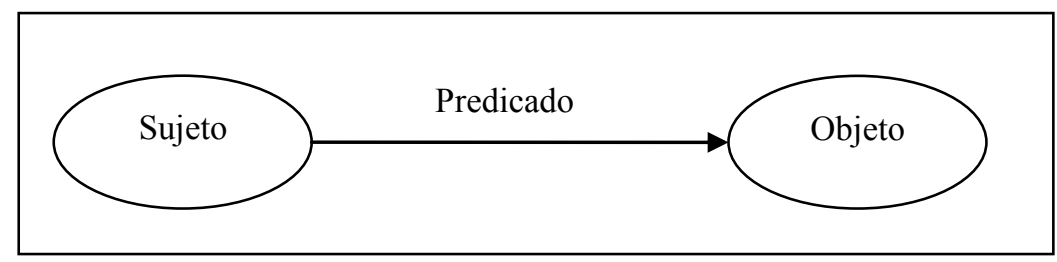

Figura 1. Sentencia RDF.

Cada uno de los elementos del triplete debe estar representado por una URI, para poder relacionarlos. Por ejemplo, supongamos que se quiere relacionar una publicación electrónica con un perfil de su autor, tendríamos lo que se muestra en la Figura 2:

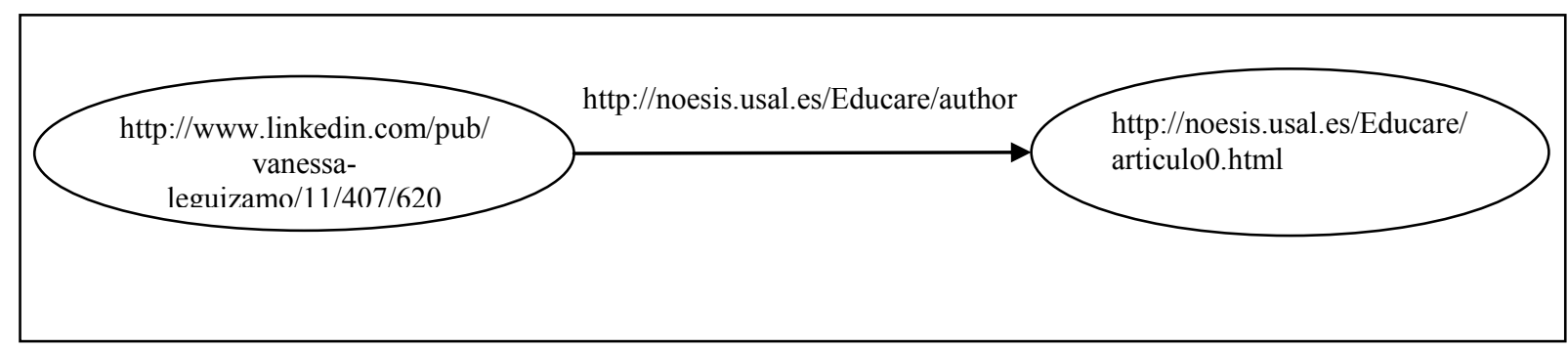

Figura 2. Sentencia RDF con URI's.

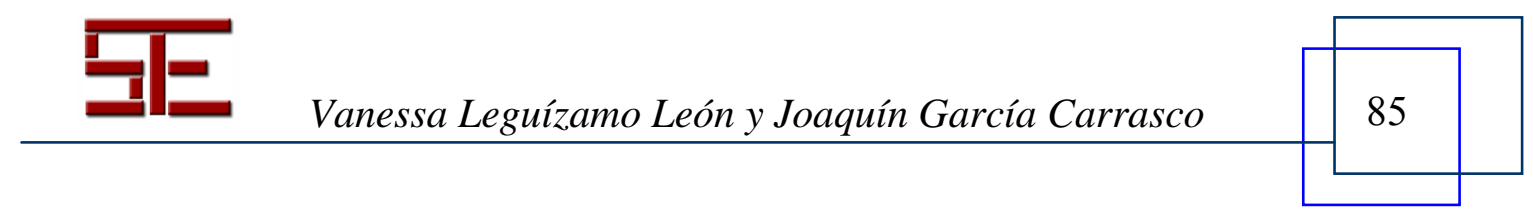




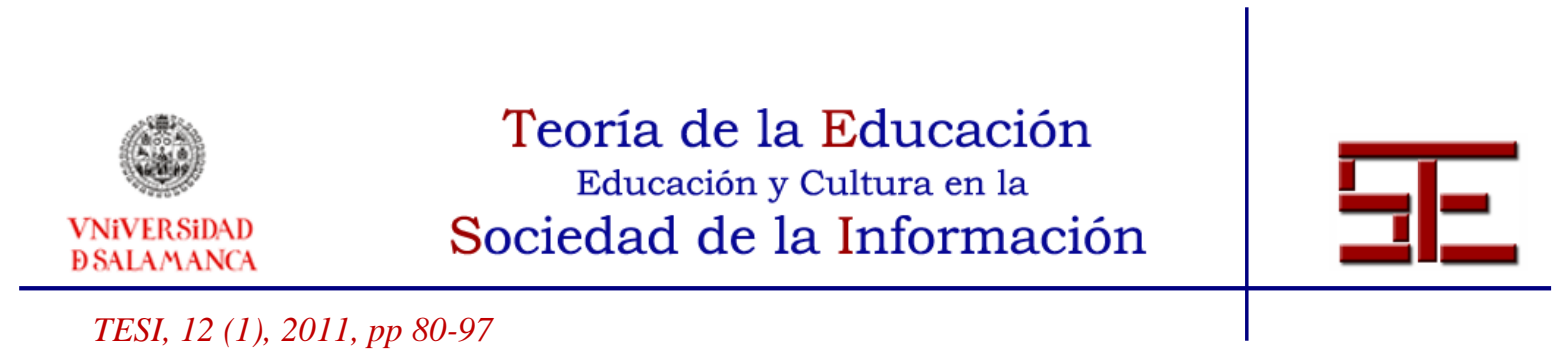

Donde http://www.linkedin.com/pub/vanessa-leguizamo/11/407/620 es el URL del perfil de Vanessa Leguízamo en Linkedln; http://noesis.usal.es/Educare/articulo0.html, la dirección de la publicación que queremos relacionar, $\mathrm{y}$ http://noesis.usal.es/Educare/creator, el predicado que los une, donde se indica que Vanessa Leguízamo es la autora de la publicación "Un acercamiento a la Web Semántica como herramienta para el aprendizaje en línea".

La Web Semántica permite también, en función de los tripletes, definir recursos basados en la orientación a objetos, estableciendo jerarquías de clases, objetos y propiedades, así como las relaciones entre ellos.

La Web Semántica incorpora también elementos técnicos que hacen posible el etiquetado y las búsquedas de documentos web. Estos elementos se describen brevemente a continuación. Estas herramientas constituyen los elementos que permiten a los desarrolladores incorporar datos que describan significado semántico en los documentos que incluyen en la Web, permitiendo que éstos sean interpretados por los ordenadores (Peis, Herrera-Viedma, Hassan, \& Herrera, 2003).

\section{2.- Elementos técnicos que incorporan contenido semántico a los documentos web}

Para incorporar semántica a los documentos colocados en Internet, es necesario definir una ontología y representarla con metadatos, e incorporar estos a los documentos, de tal manera que describan, al menos, el contenido, el significado y la relación de los datos allí contenidos. Estos metadatos deben estar bien estructurados y escritos en algún metalenguaje que pueda ser interpretado por un ordenador. A continuación se explican estas definiciones.

\subsubsection{Metadatos}

Del griego meta, más allá, y del latín datum, dato: más allá del dato, o datos acerca de los datos. Los documentalistas están familiarizados con los metadatos desde hace décadas, aunque utilizan para ellos otro nombre. Los metadatos son información acerca de la información, o datos sobre datos; un ejemplo son los catálogos de las bibliotecas, donde se tienen fichas con información referente a cada libro. Lo mismo sucede con las referencias bibliográficas de las bases de datos documentales, que describen elementos clave de cada documento que almacenan; por ejemplo, autor, título, año de publicación, ubicación, entre otras, y que a su vez facilitan su acceso y recuperación. En la Figura 3 se muestra una captura de pantalla de la base de datos del Servicio de Bibliotecas de la

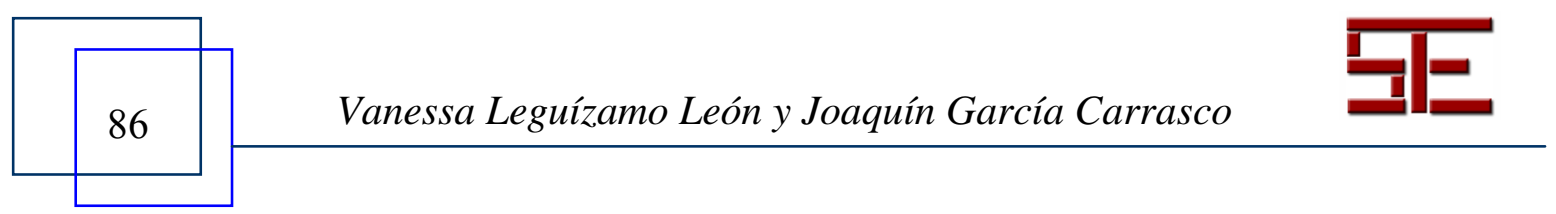




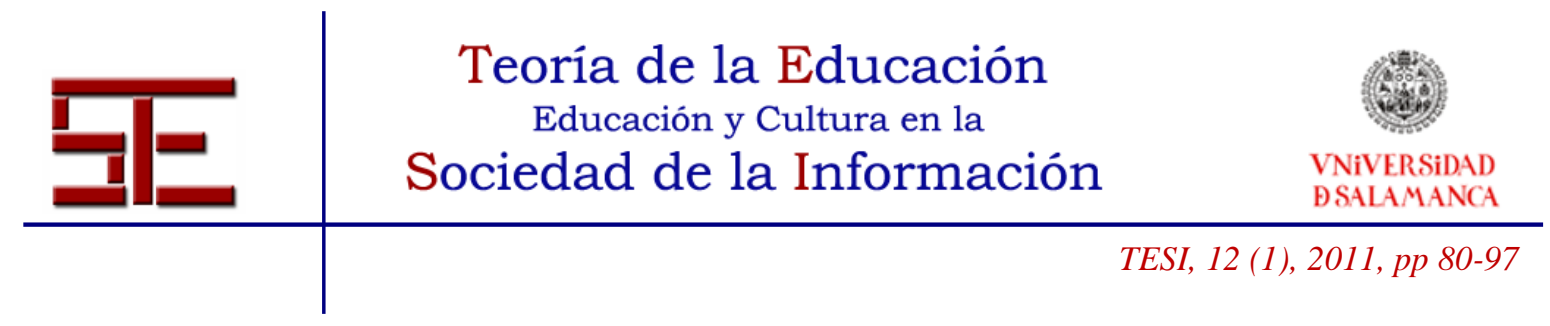

Universidad de Salamanca, donde se ha hecho una búsqueda por "palabra clave", y el sistema devuelve el conjunto de datos que definen el recurso, es decir, sus metadatos.

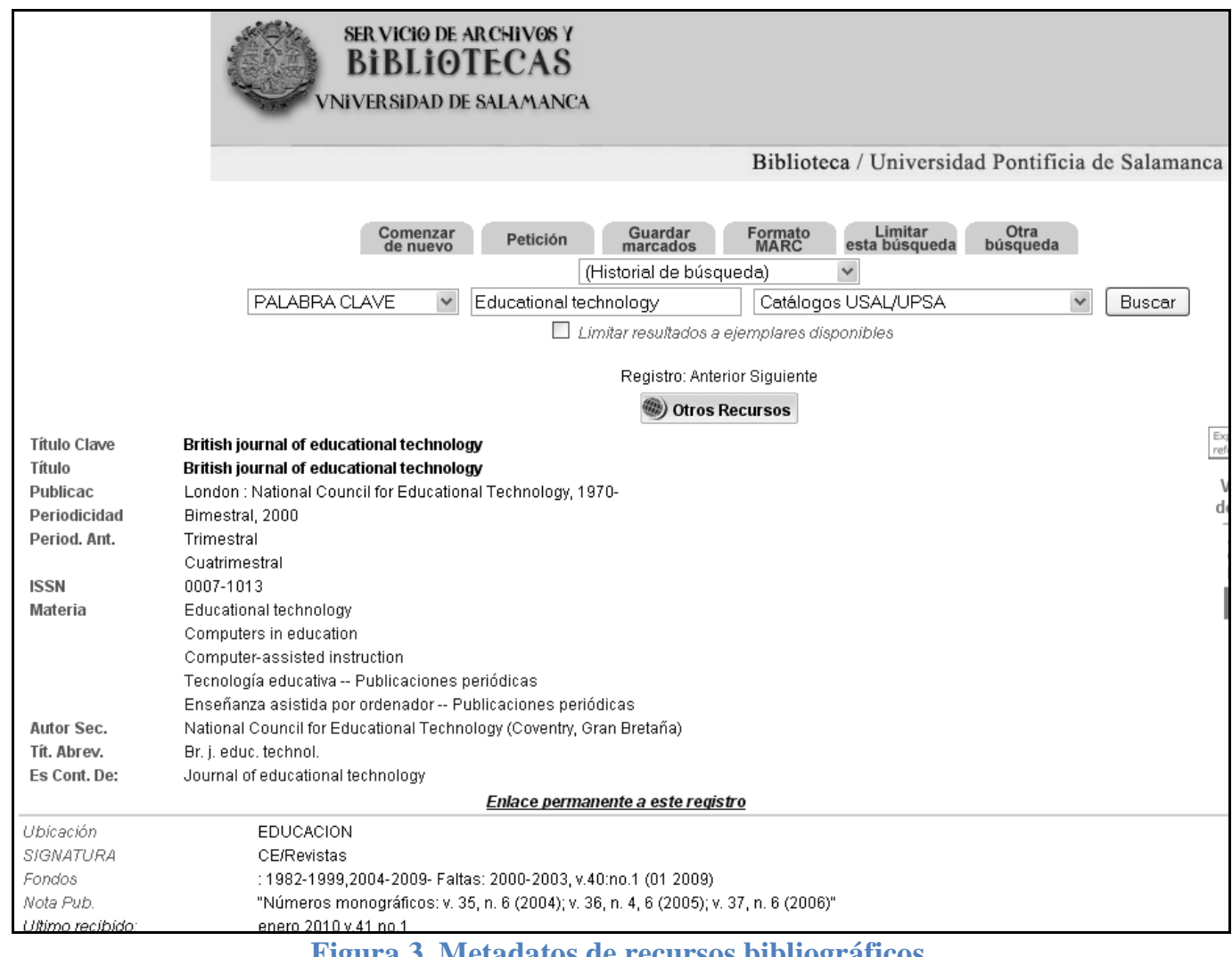

En el lenguaje documental se habla de documentos primarios, que hacen referencia al material o información original, artículo, revista o libro, y documentos secundarios, que son las fichas que se hacen de cada recurso y que contienen sus descriptores. En la terminología web, se habla entonces de recursos y metadatos, donde los recursos se corresponden con los documentos primarios y los metadatos con los secundarios.

Los metadatos son relativos al contexto en el cual se encuentren los recursos a describir, y del tipo de estos recursos. Así, los metadatos necesarios para una base de datos documental no serían necesariamente los mismos, si se tiene un repositorio de imágenes u obras de arte, en este último caso sería necesario incorporar también descripción de la técnica utilizada y el tamaño, por ejemplo, cuestiones que no son necesarias para

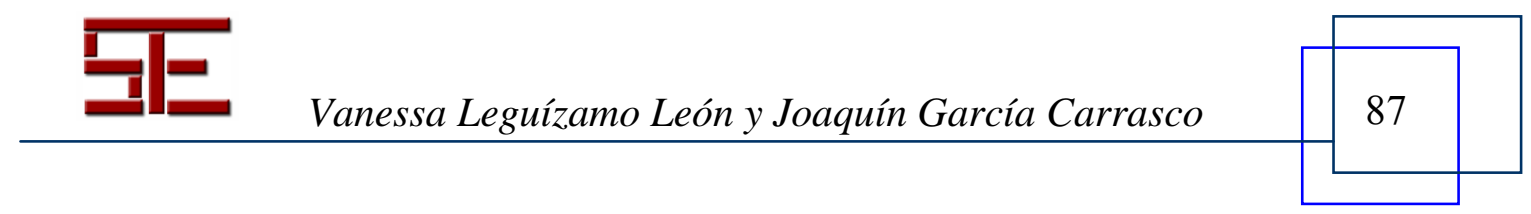




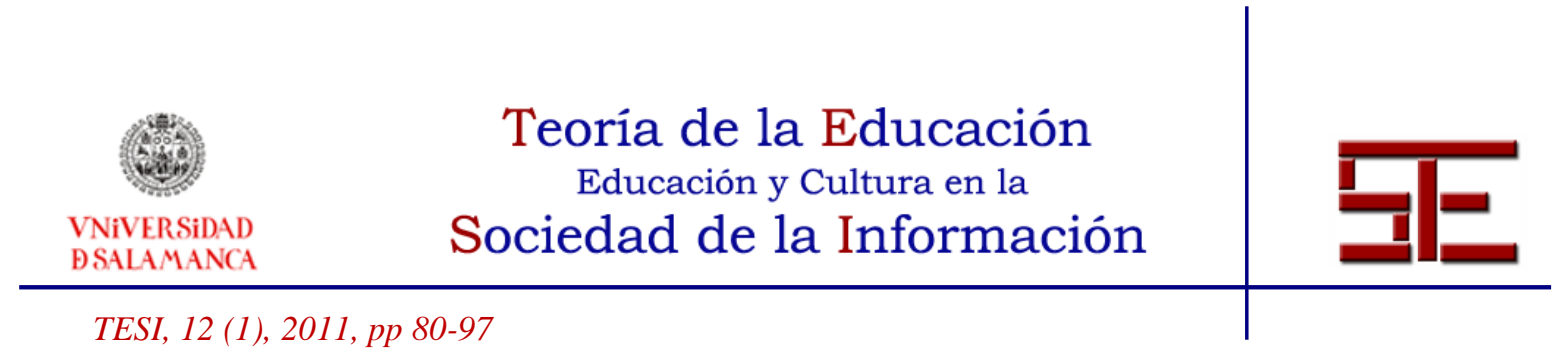

describir documentos. Si describiéramos los metadatos de la página mostrada en la Figura 3, tendríamos lo siguiente:

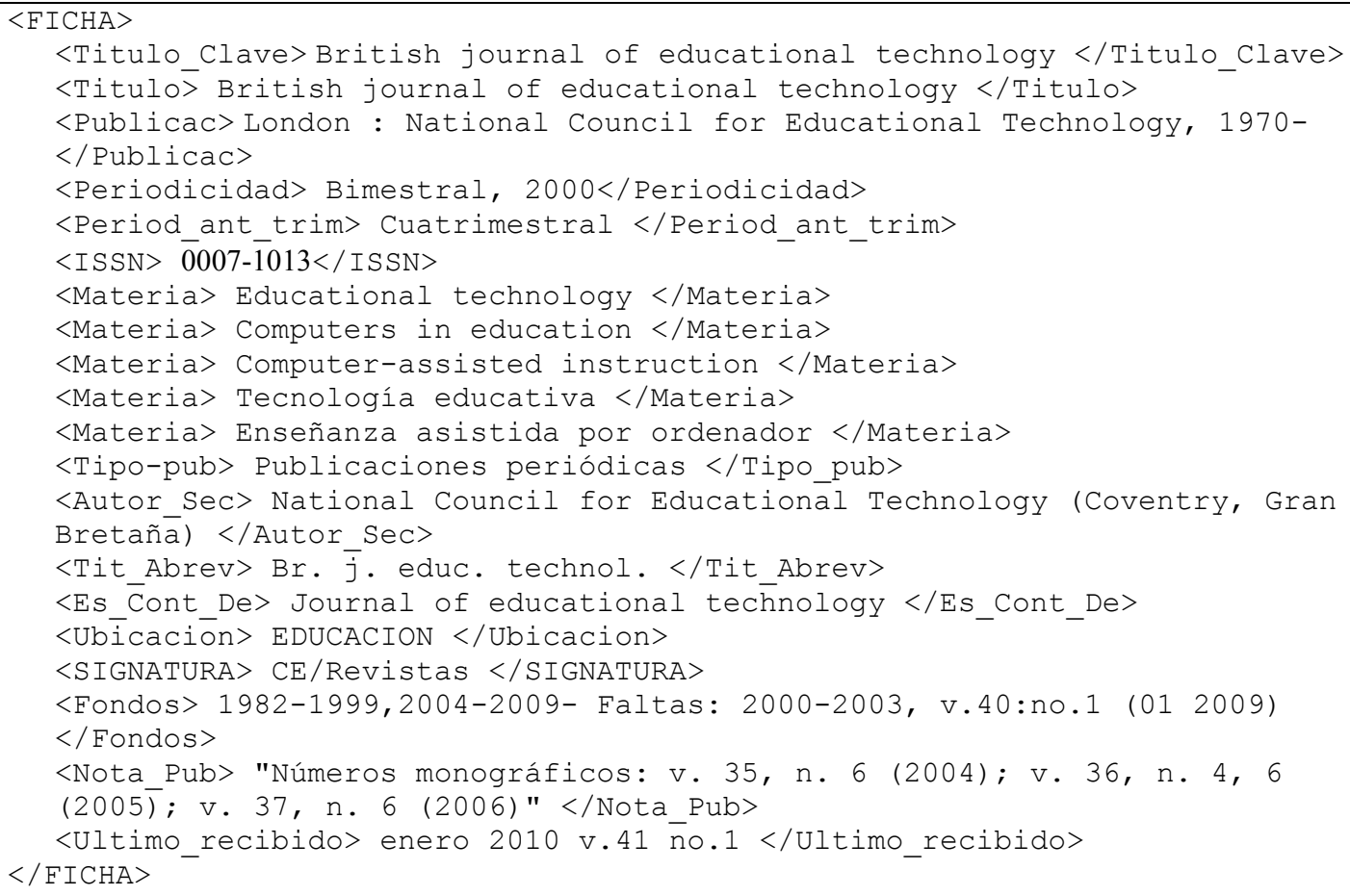

Estos metadatos, definidos en un lenguaje particular, como XML o RDF, son comprensibles e interpretables por un ordenador, lo que permite realizar búsquedas por cada uno de los campos descritos, tal como se hace en una base de datos bibliográfica. Esto permite agilizar las búsquedas por contexto, que es una de las funciones principales de los metadatos en la web Semántica, donde previamente al etiquetado de los documentos, se define una ontología, que es implementada con la incorporación de metadatos a los documentos Web. Para etiquetar los documentos existen diversos editores de metadatos, que permiten, a través de una interfaz amigable, incorporar metadatos a los documentos. Para el caso particular de materiales educativos, podemos citar la herramienta $\operatorname{LomPad}^{l}$, que permite añadir metadatos a los objetos de aprendizaje o a cualquier material educativo, cuya interfaz se muestra en la Figura 4, o el caso de la herramienta eXeLearning ${ }^{2}$, que, además de permitir la incorporación de metadatos a los

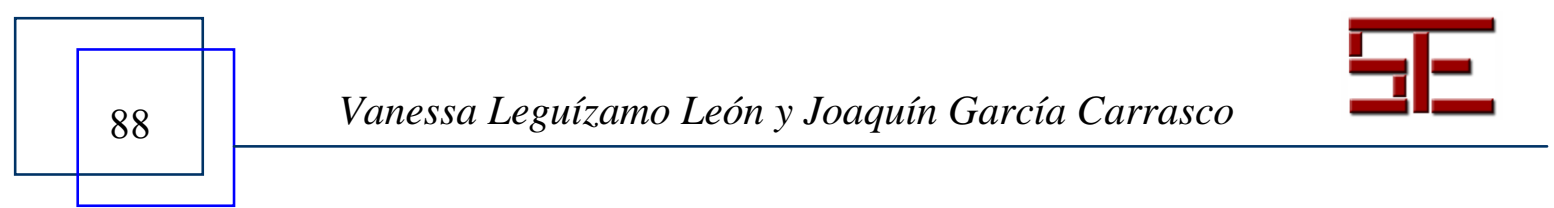




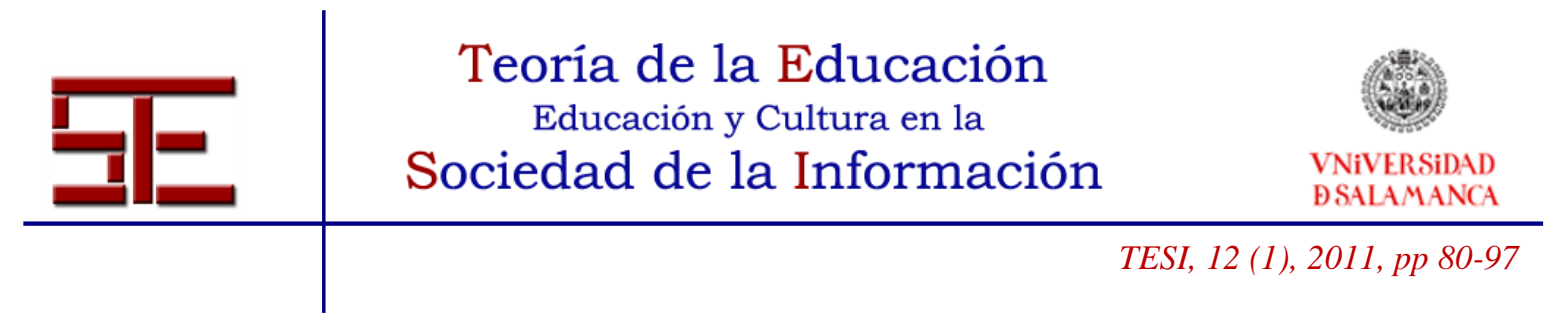

documentos, es una herramienta de autor que ayuda a los profesores en el diseño, desarrollo y publicación de materiales educativos para la Web. En la Figura 5 se muestra la interfaz de eXeLearning.

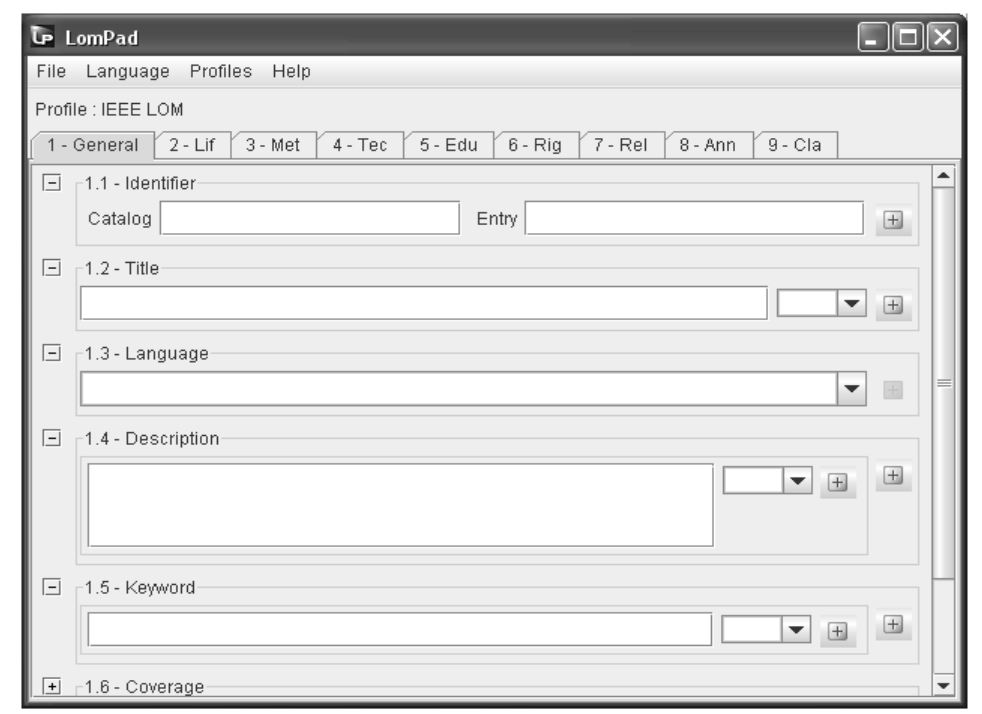

Figura 4. Interfaz de LomPad.

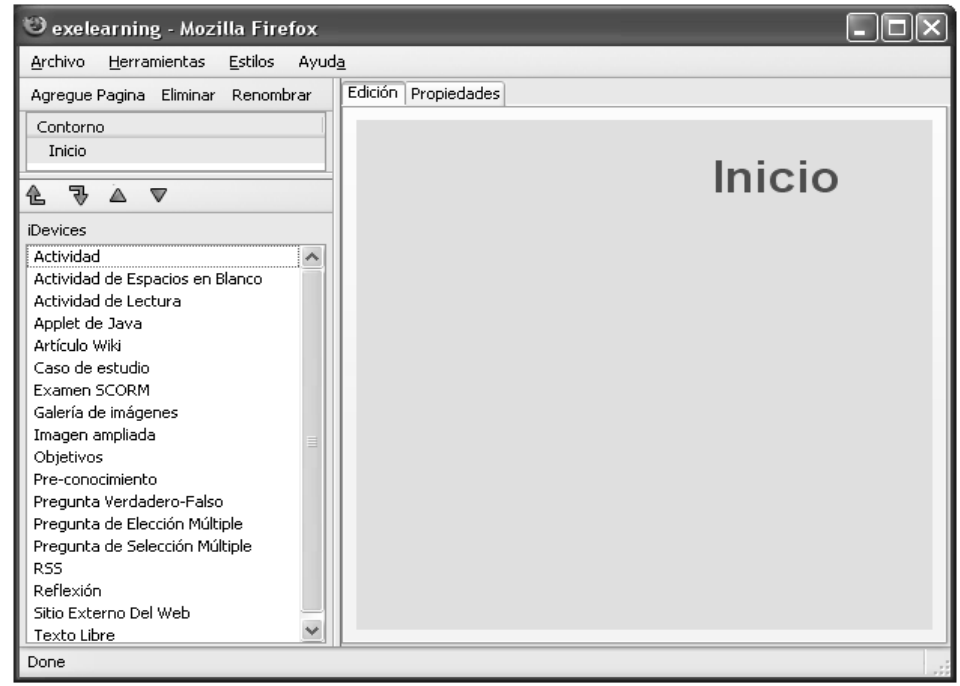

Figura 5. Interfaz de eXeLearning. 


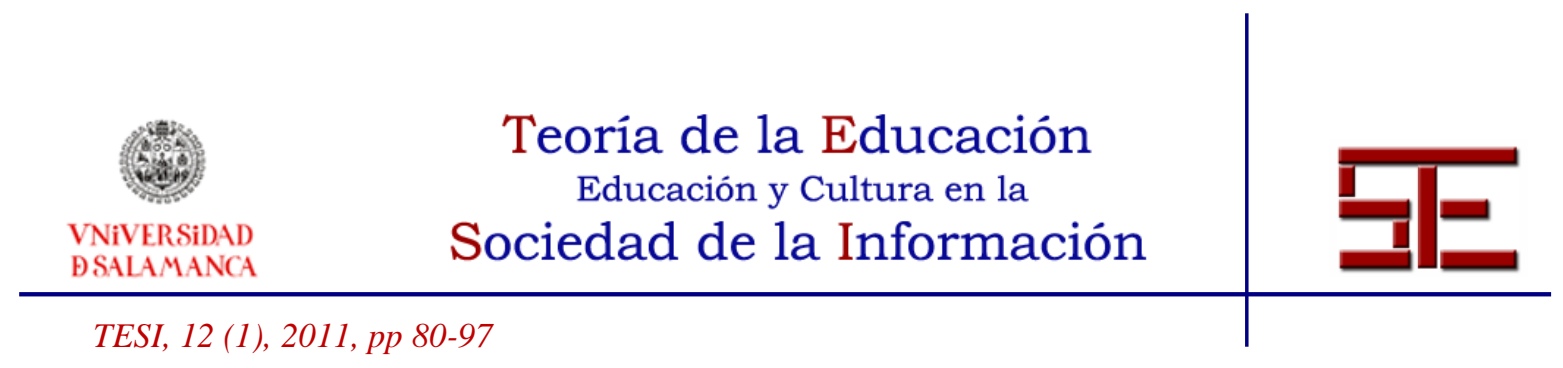

\subsubsection{Ontologías}

Las ontologías desde el punto de vista de la filosofía tratan la naturaleza de la existencia, las categorías de entidad de las cosas que existen. Propone el estudio de todo lo que existe, qué es, cómo es y cómo es posible. La ontología se ocupa de la definición del ser y de establecer las categorías fundamentales o modos generales de ser de las cosas a partir del estudio de sus propiedades. Con base en esto, se definió en el área de la biología una ontología que permite clasificar a todos los seres vivos conocidos, que se muestra resumida en su primer nivel en la Figura 6.

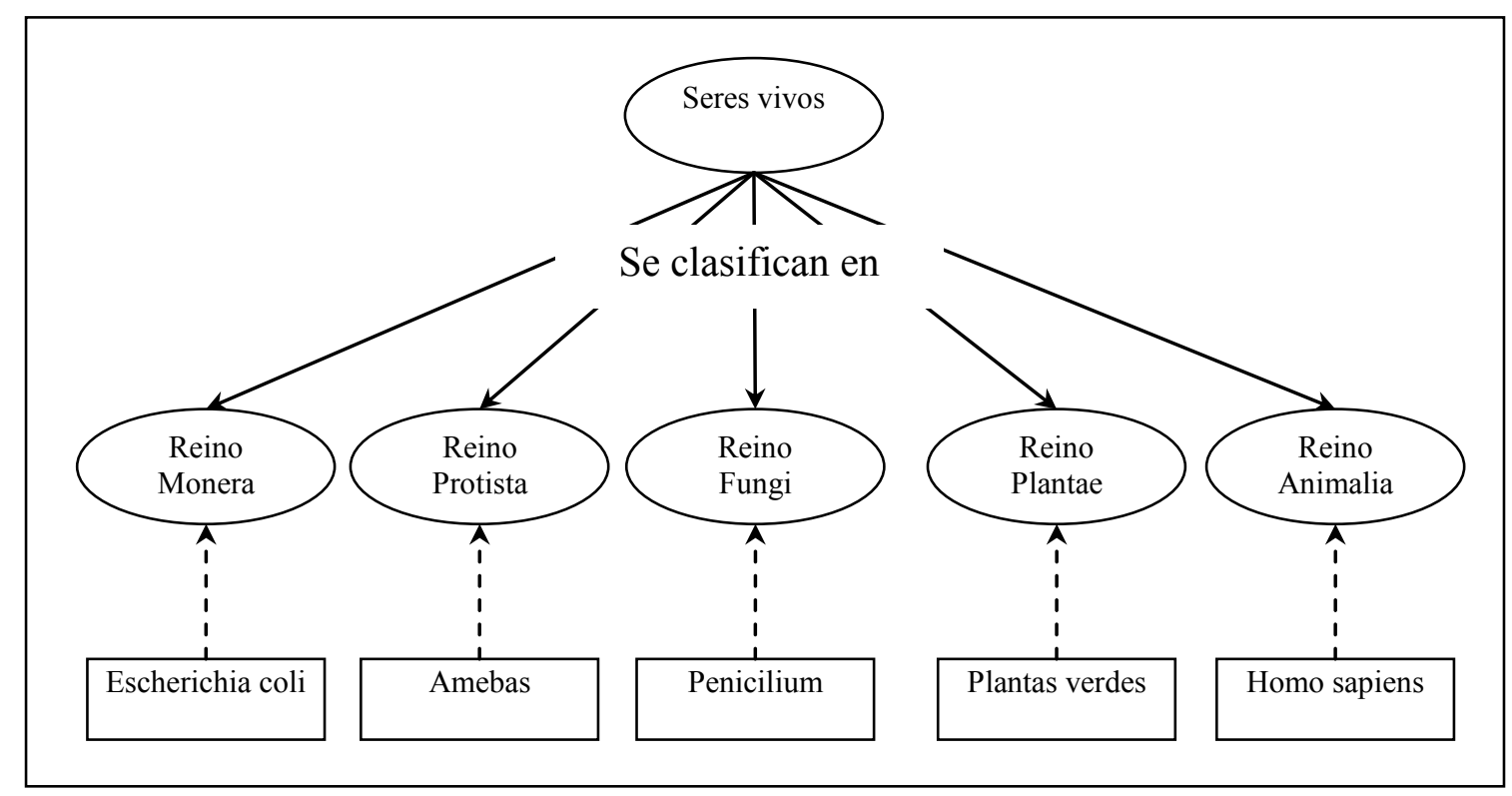

Figura 6. Ontología resumida de los seres vivos.

Los investigadores en Inteligencia Artificial y Web adoptaron el término de ontología y establecen un área de la informática, la cual se ocupa de definir formalmente relaciones entre conceptos. Nykänen (2004) define que una ontología es una especificación formal y explícita de una conceptualización compartida respecto un dominio particular.

La ontología es la manera más habitual para añadir significado semántico a la Web. Para lograr esto, la ontología debe estar conformada por una taxonomía y un conjunto de reglas de inferencia. La taxonomía define clases de objetos y las relaciones entre ellos. En la Figura 7 se muestra la ontología para clasificar los tipos de datos básicos en

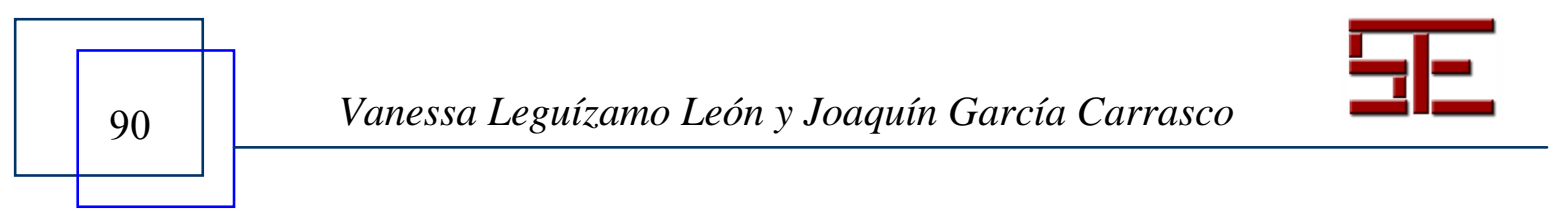




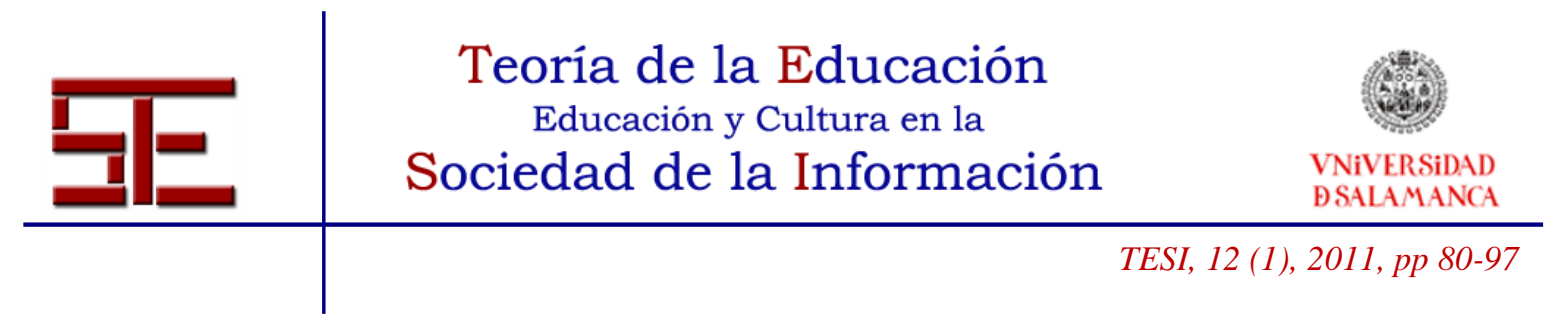

un lenguaje de programación. Los tipos de datos se clasifican en elementales y estructurados de acuerdo al número de componentes que tiene, a su vez los tipos elementales pueden ser los enteros, reales, lógicos. Los tipos de datos estructurados se clasifican a su vez en homogéneos o heterogéneos, dependiendo de si sus componentes son todos iguales o pueden ser diferentes (Leguízamo, 2007).

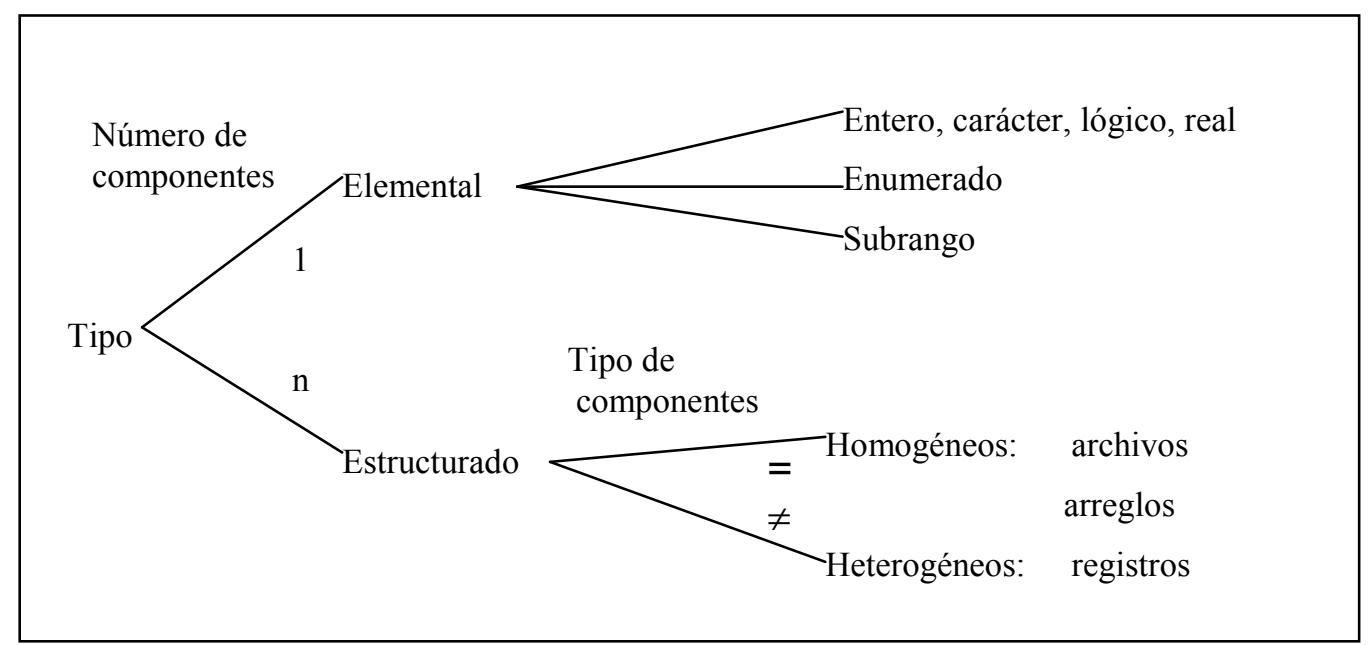

Figura 7. Ontología para la clasificación de tipos de datos.

Las ontologias pueaen potenciar eı runcionamiento de ia wev de mucnas maneras, pueden ser utilizadas de manera simple para mejorar la exactitud de las búsquedas en Internet, buscando sólo en aquellas páginas que refieren conceptos precisos de alguna de las palabras solicitadas. Aplicaciones más avanzadas pueden utilizar ontologías para relacionar la información en una página con estructuras de conocimiento y sus reglas de inferencia asociadas (Berners-Lee, Hendler, \& Lassila, 2001; Davis, Studer, \& Warren, 2006).

Supongamos ahora que se quiere desarrollar una Web Semántica. Lo primero que se debe definir es el dominio de la aplicación o área de conocimiento en la cual se va a situar el sitio que se va a desarrollar. Supongamos también que hemos definido el contexto, la página web de un hospital. En este caso, se define una ontología para clasificar los servicios de ese hospital, con la intención de que un paciente pueda saber qué médico de una especialidad puede atenderlo mañana y que esté afiliado a su seguro médico. En la Figura 8 se muestra la ontología para este contexto:

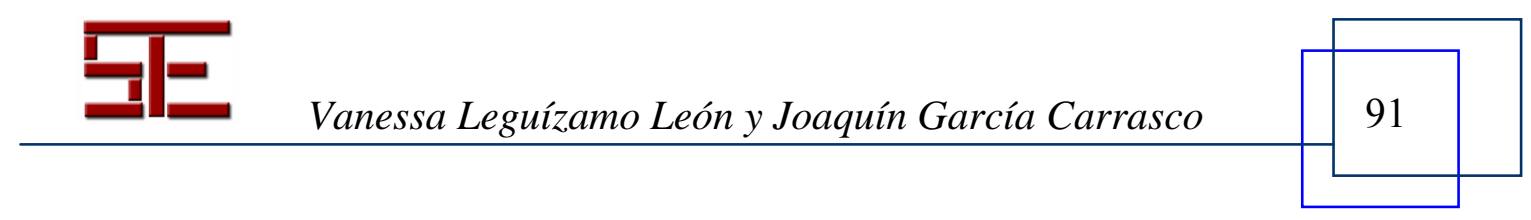



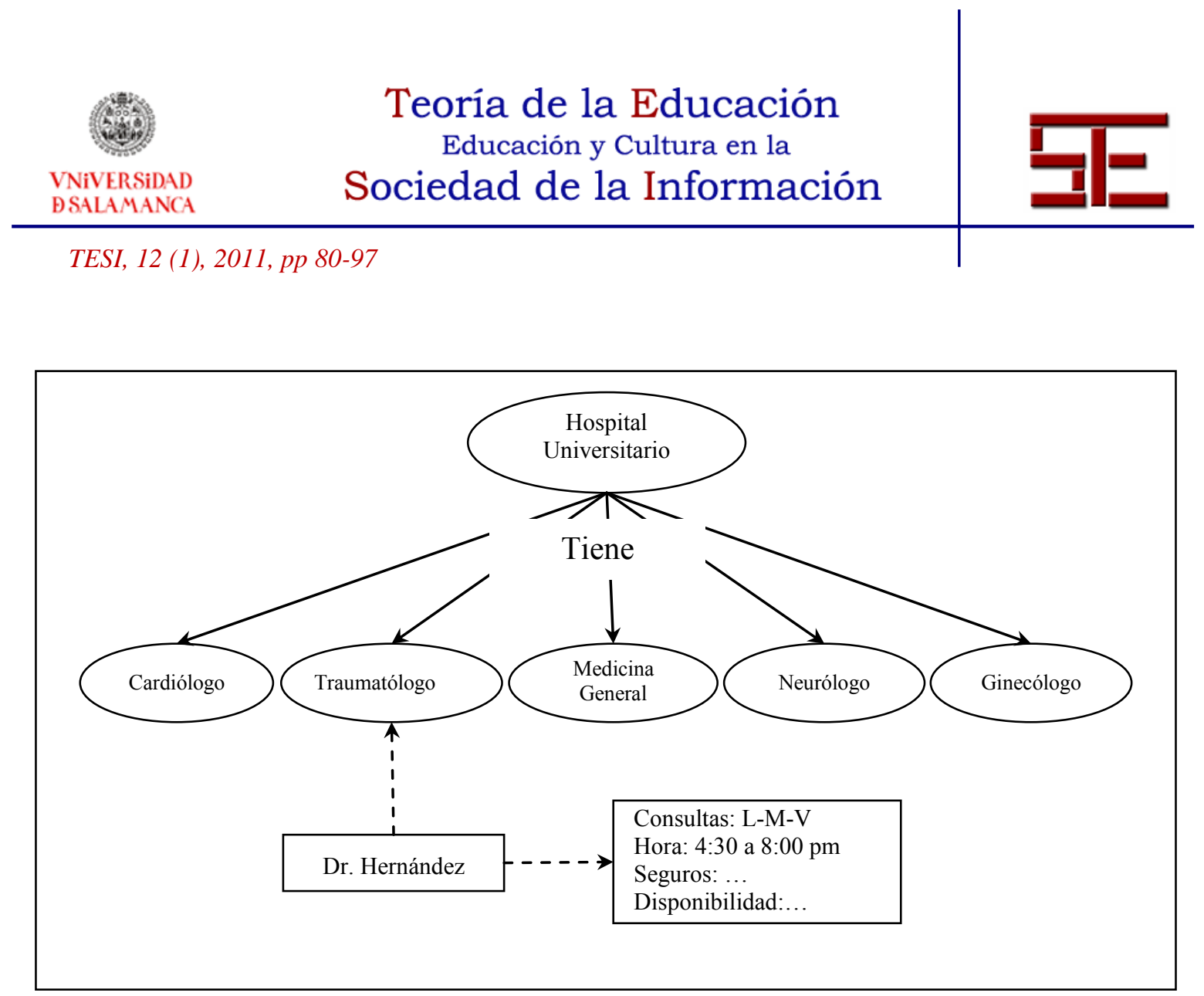

Figura 8. Ontología para una consulta médica.

Si un paciente desea una consulta con un traumatólogo, al hacer su solicitud al sistema, indicando la especialidad del médico, el día que quiere la consulta y la restricción de que trabaje con su seguro médico, el sitio web devolvería la opción que se ajuste a su petición, por ejemplo, el Dr. Hernández tiene consulta disponible mañana, viernes, a las 5:00 pm y está afiliado a su seguro médico.

Técnicamente, la ontología podría ser implementada en lenguaje OWL, relacionado cada uno de los recursos (especialidad con nombre del médico, nombre del médico con disponibilidad, nombre del médico con seguro médico, entre otras) utilizando RDF y mostrado y formateado con XML para ser presentado finalmente al usuario. También tendría que desarrollarse un programa de ordenador, o agente, que realice las búsquedas sobre la ontología descrita, haciendo comparaciones entre los descriptores dados y los metadatos de los diferentes documentos y bases de datos disponibles, para finalmente mostrar el resultado requerido por el usuario.

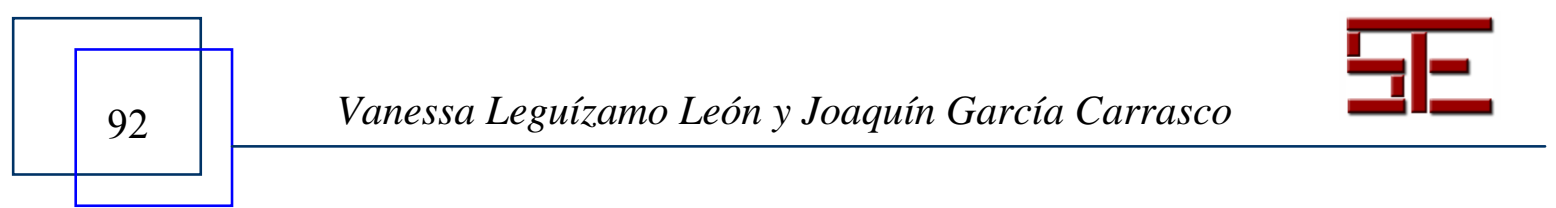




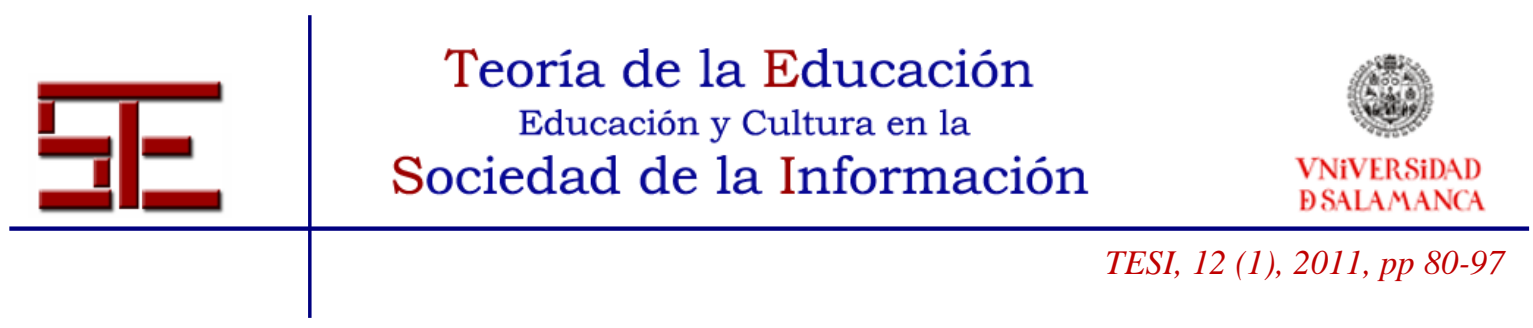

\section{4.- APLICACIONES DE LA WEB SEMÁNTICA EN ENTORNOS VIRTUALES DE FORMACIÓN}

Tal y como plantean Panteleyev et al. (2002), la visión de la Web Semántica está basada en dos ideas principales: añadir datos semánticos a los recursos que se encuentran en la Web y la creación de agentes inteligentes capaces de entender y operar con los recursos a un nivel semántico.

En el contexto educativo, es bien sabido que Internet es un proveedor auténtico de materiales interactivos, que brinda la posibilidad de encontrar múltiples documentos en casi cualquier temática educativa, como si de una gran biblioteca se tratara, donde es posible conseguir artículos, libros, mapas, imágenes, vídeos, sonidos, software educativo, permitiendo además compartir contenidos con cualquier tipo de audiencia en cualquier lugar del mundo; pero, donde la información no está ordenada bajo ningún criterio especial, ni utilizando ninguna codificación estándar, por lo que no puede ser pensada como una base de datos. Además, cada página ha sido desarrollada de acuerdo a los criterios y objetivos particulares de su autor. Dada la gran extensión de Internet, es necesario tener criterios muy claros para realizar las búsquedas, para poder discernir entre qué seleccionar y cómo distinguir lo relevante de lo que no lo es (Leguízamo, 2008).

En un ambiente de aprendizaje esta situación puede llegar a ser complicada para los estudiantes, porque necesitan conseguir información de un tópico particular relacionado con sus actividades de clase; es posible que el estudiante consiga información del tópico que busca, pero que no sea fiable; es decir, la información encontrada puede estar en desuso, no estar verificada o incluso ser totalmente inválida, obteniendo un aprendizaje basado en una información no correcta. Esta situación requeriría la intervención del profesor para reconducir el proceso de aprendizaje; si el conocimiento utilizado por el estudiante no fuera válido, habría de iniciar el proceso de desaprender lo aprendido, y el de reaprender el conocimiento facilitado por el profesor.

En este sentido, Koper (2004) indica que la aplicación de la Web Semántica en contextos educativos puede ayudar a disminuir estos problemas, contribuyendo en la realización de tres objetivos: incrementar la efectividad de la educación, hacer más atractiva la educación y disminuir la carga de trabajo o disminuir los costos. Plantea que la Web Semántica puede contribuir principalmente en dos áreas, a saber:

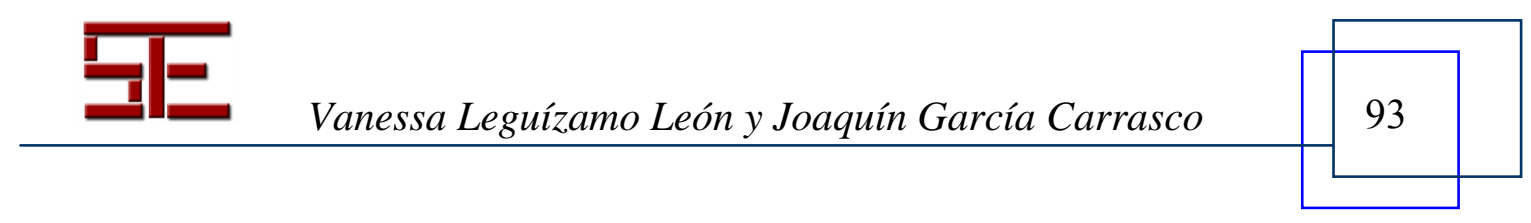




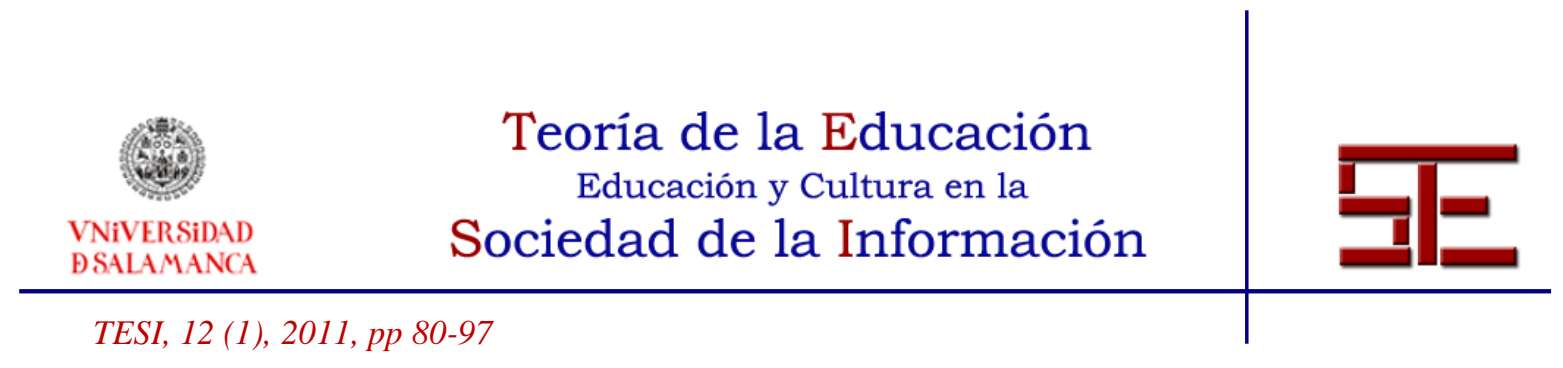

- Ayudando al equipo de trabajo a hacer algunas de sus tareas más flexibles, hacer los aspectos educativos en línea más eficientes y menos aislados, esto incluye las tareas de desarrollo de cursos en línea, ayudar al aprendiz en sus tareas, mejorar las evaluaciones y manejo y administración de cursos.

- Ayudando a las personas que cumplen diferentes roles (aprendices, tutores y proveedores de contenido), a desempeñar sus tareas más efectiva y eficientemente en espacios de aprendizaje grandes, distribuidos, basados en problemas, multi-actores, multi-recursos, crear y modificar ambientes de aprendizaje centrados en el aprendiz, no lineales y autodirigidos.

En el caso particular de la educación en línea, donde el aprendizaje no es dirigido por el instructor, sino que los estudiantes tienen libertad de acceder al material disponible en un orden no predefinido y componer su aprendizaje de la manera que más se adapte a ellos, puede hacerse necesario incorporar información a los documentos disponibles para la consulta de los estudiantes, que permita indexar y recuperar esta información de manera efectiva.

El uso de metadatos es una respuesta natural para solucionar este problema, y de hecho ya ha sido implementado en librerías en línea desde hace algún tiempo. En e-Learning, es común que los docentes indiquen asociaciones entre sus materiales, o definan las propiedades educativas o pedagógicas de los documentos, o el orden en el que los estudiantes deben acceder a estos materiales. Sin embargo, toda esta información no está reflejada en los documentos cuando se colocan en Internet, por lo que no puede ser manejada automáticamente por los ordenadores. Si se incorporan elementos semánticos a los documentos que colocan los docentes en Internet, reflejando las relaciones entre ellos, una aplicación web podría actuar como agente, que ayude a los estudiantes a realizar un recorrido efectivo sobre el contenido del curso en línea (Antoniou \& Van Harmelen, 2004).

Las ontologías en ambientes de aprendizaje pueden ser utilizadas para facilitar a los estudiantes el acceso a la información contenida allí, por ejemplo, en el caso de aquellos cursos que tienen audiencias heterogéneas, donde cada uno de ellos tiene diferentes niveles de conocimiento en el contexto del curso. Se pueden definir ontologías para clasificar el contenido que deben revisar los estudiantes, dependiendo de su nivel de conocimiento, estableciendo relaciones entre conceptos, como "es parte de", o "requiere de". Un ejemplo de estas relaciones puede definirse en función del lenguaje Java, este es parte de los Lenguajes de Programación, y los Lenguajes de Programación para poder ser utilizados requieren conocimientos de algoritmia. Así, un ordenador podría inferir

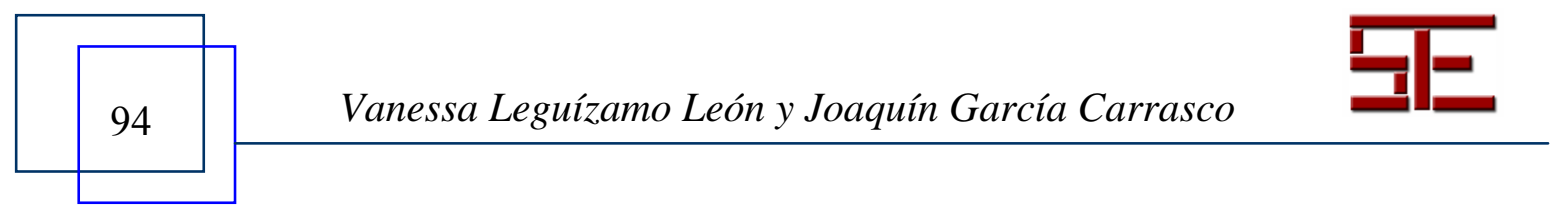




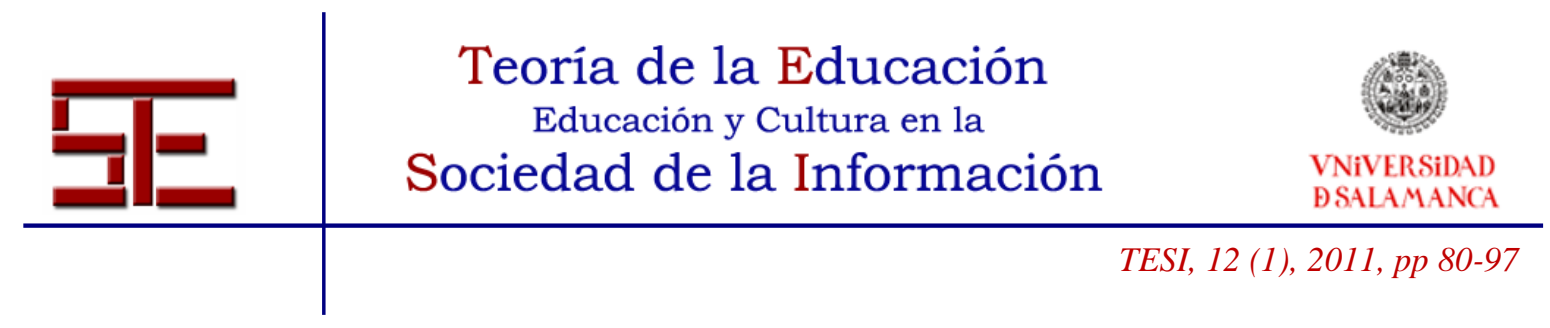

que para utilizar el lenguaje de programación Java, el estudiante debe tener conocimientos de algoritmia y, en caso de no tenerlos, proveérselos. También se pueden definir ontologías para establecer aspectos pedagógicos en los materiales dispuestos, por ejemplo, para clasificarlos como tutoriales, ejemplos, ejercicios, evaluaciones, entre otros. Otro tipo de ontología puede utilizarse para definir estructuras lógicas entre los materiales, al tener conceptos que son jerárquicos, y la navegación entre ellos se define por relaciones de orden, como anterior, siguiente, inicio o fin de los documentos estudiados (Antoniou \& Van Harmelen, 2004).

Si bien la Web Semántica surge formalmente con el trabajo de Berners-Lee en el 2001, con anterioridad a esta fecha existían trabajos que apuntaban en esta línea, y particularmente en su vinculación con la pedagogía, como es el caso del trabajo desarrollado en el Royal Institute for Technology (KHT) en Suecia, por Neave y su grupo de trabajo. Sus Jardines del Conocimiento (Naeve, 1997) son ambientes de aprendizaje que pueden ser usados para explorar redes de ideas. Ellos desarrollaron también la idea de Web Conceptual (Naeve, Nilsson, \& Palmer, 2001), como una capa de la Web Semántica tratando de hacer que esta fuera tan accesible a los humanos como a las máquinas, usando mapas conceptuales gráficos, que incluyen conceptos y relaciones entre esos conceptos, así como el acceso a los contenidos asociados.

\section{5.- APORTES DE LA WEB SEMÁNTICA A LOS CONTEXTOS EDUCATIVOS}

La Web Semántica tiene un inmenso potencial en el mundo de la enseñanza y el aprendizaje, y este potencial es especialmente relevante en cuanto contribuya a catalizar la creación y recolección de conocimiento disperso u oculto. Si el esfuerzo invertido en alimentar Internet de datos ha sido, es y será muy importante, no lo es menor en lo que se refiere a la recuperación de esos datos, es decir, la búsqueda a partir de datos semánticos. La búsqueda semántica está cambiando y mejorando la forma de buscar y encontrar información en las grandes bases de información que constituyen la web. Con los avances en el área de computación sensible a la semántica, han surgido algunos buscadores "inteligentes", herramientas que están comenzando a responder en el lenguaje natural del ser humano ${ }^{3}$. Estas herramientas aún están en desarrollo y tienen acceso limitado, pero son acercamientos prometedores de lo que puede surgir en un futuro muy cercano.

El informe Horizon, en su edición iberoamericana del 2010 (García, Peña-López, Johnson, Smith, \& Haywood, 2010), muestra los resultados de su investigación en esta línea, en el cual describen las tecnologías emergentes con mayor potencial de impacto

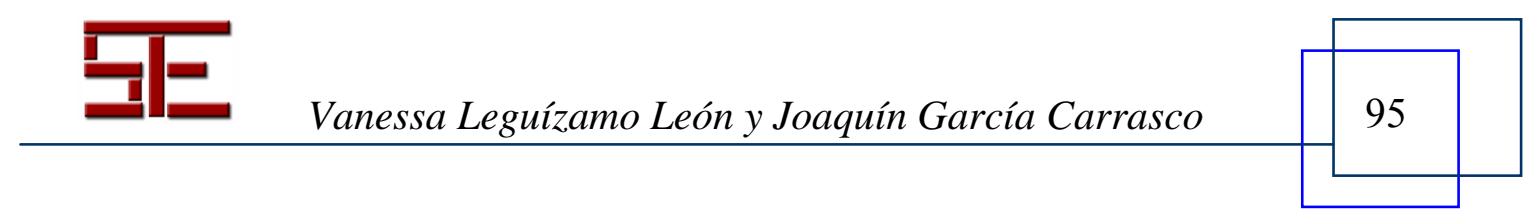




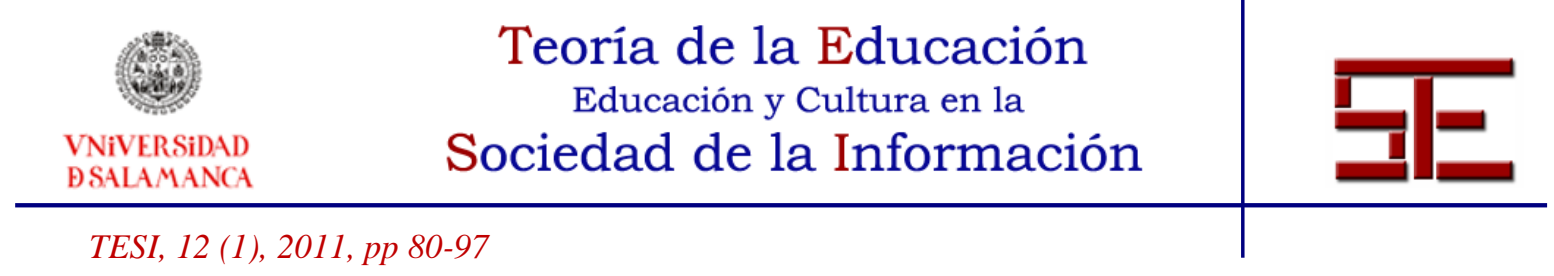

en la enseñanza, el aprendizaje, la investigación y la expresión creativa en el ámbito educativo global. Entre las tecnologías que mencionan con mayor potencial incluyen a la Web Semántica, con un horizonte prospectivo de cuatro a cinco años para su auge, estableciéndola como tecnología emergente con mucho que aportar en el campo educativo y científico. Establecen en este informe que el mayor campo de acción de esta tecnología está orientado a hacer las búsquedas de información más precisas y a la obtención de resultados más ricos y relevantes. Según este informe, la Web Semántica hace más fácil la explicitación de conocimiento tácito, uso este que se torna especialmente valioso a la hora de recuperar conocimiento disperso y generado fuera de los entornos tradicionales del saber. Por otra parte, la información recuperada utilizando esta tecnología no sólo tiene mayor calidad, sino que puede ser reutilizada en contextos distintos a los que originalmente concebida.

\section{6.- AGRADECIMIENTOS}

La presente investigación ha sido financiada por el Consejo de Desarrollo Científico y Humanístico de la Universidad Central de Venezuela. Está siendo llevada a cabo en el Laboratorio de diseños educativos multimedia $\mathrm{y}$ teleeducación del Instituto Universitario de Ciencias de la Educación de la Universidad de Salamanca.

\section{7.- BIBLIOGRAFÍA.}

Antoniou, G. \& Van Harmelen, F. (2004). A Semantic Web Primer. Massachusetts Institute of Technology.

Berners-Lee, T. \& Hendler, J. (2001). Scientific publishing on the „semantic web"e Nature, 410 (6832).

Berners-Lee, T., Hendler, J. \& Lassila, O. (2001). The semantic web: a new form of web content that is meaningful to computers will unleash a revolution of new possibilities. Scientific American.

Davis, J., Studer, R. \& Warren, P. (2006). Semantic Web Technologies, trends and research in ontology-based systems. Wiley.

García, I., Peña-López, I., Johnson, L., Smith, R., Levine, A. \& Haywood, K. (2010). Informe Horizon: Edición Iberoamericana 2010. Austin, Texas: The New Media Consortium.

Koper, R. (2004). Use of the Semantic Web to Solve Some Basic Problems in Education. Journal of Interactive Media in Education, 6.

Leguízamo, A. V. (2007). Algoritmos y Programación, Lecturas en Ciencias de la Computación, vol. ND 2007-1. Caracas: Universidad Central de Venezuela.

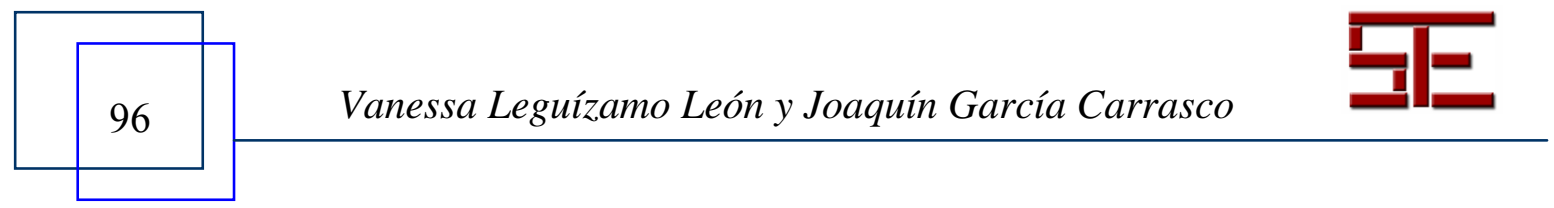




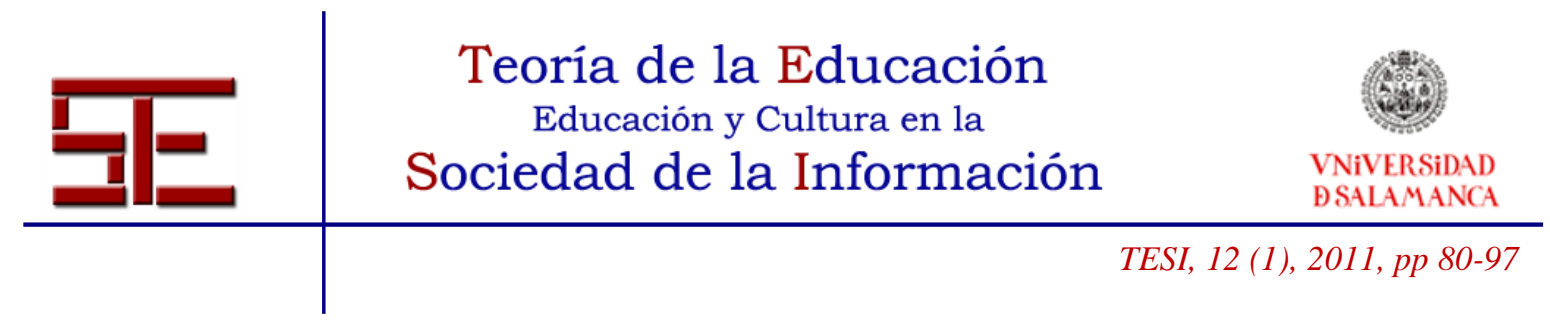

- (2008). The Web Semantic approach like tool for the e-learning. CEUR Workshop Proceedings, 361. Retrieved from http://CEUR-WS.org/Vol-361/paper12.pdf.

Naeve, A. (1997). The garden of knowledge as a knowledge manifold - a conceptual framework for computer supported subjective education (No. TRITA-NAD9708): Department of Numerical Analysis and Computer Science, KTH, Stockholm.

Naeve, A., Nilsson, M. \& Palmer, M. (2001). The conceptual web-our research vision. Paper presented at the First Semantic Web Working Symposium, Stanford University.

Nykänen, O. (2004). Metadata for Learning Resources: Technologies and Directions of the Semantic Web - A Brief Review. Paper presented at the IEEE International Conference on Advanced Learning Technologies (ICALT ${ }^{e e}$ 04).

Panteleyev, M. Puzankov, D., Sazykin, P. \& Sergeyev, D. (2002). Intelligent Educational Environments Based on the Semantic Web Technologies. Paper presented at the IEEE International Conference on Artificial Intelligence Systems (ICAIS ${ }^{\text {ee }} 02$ ).

Peis, E., Herrera-Viedma, E., Hassan, Y. \& Herrera, J. C. (2003). Análisis de la web semántica: estado actual y requisitos futuros. El profesional de la información, $12(5)$.

World Wide Web Consortium W3C. (2006). Guía Breve de Web Semántica. Retrieved marzo 2007, from http://www.w3c.es/Divulgacion/Guiasbreves/WebSemantica.

\section{NOTAS}

${ }^{1}$ Desarrollado por el Laboratoire en Informatique Cognitive et Environnements de Formation (LICEF) y $\begin{array}{lllll}\text { L'université à distance de l'ÚQÀM } & \text { (TÉLUC). }\end{array}$ http://helios.licef.ca:8080/LomPad/en/index.htm

${ }^{2}$ Herramienta de autor de código abierto, desarrollada por la Universidad de Auckland, la Universidad Tecnológica de Auckland, y la Escuela Politécnica Tairawhiti. Disponible en http://exelearning.org

3 Algunos ejemplos son los buscadores Wolfram|Alpha (http://www.wolframalpha. com), TrueKnowledge (http://trueknowledge.com) o Kngine (http://kngine.com/), que utilizan tecnología de Web Semántica para realizar búsquedas sobre sus bases de datos.

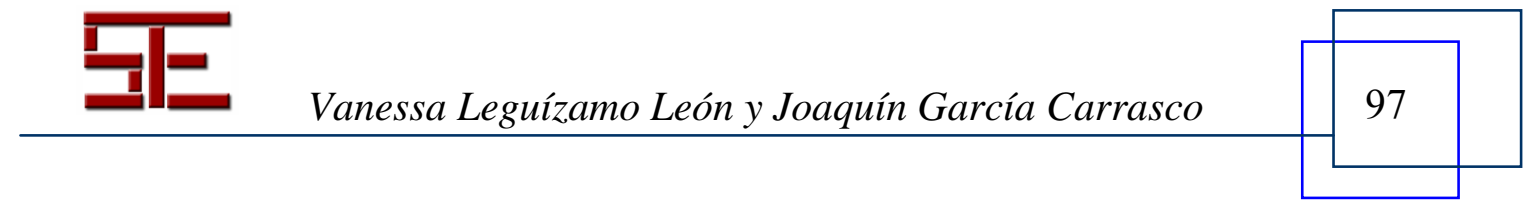




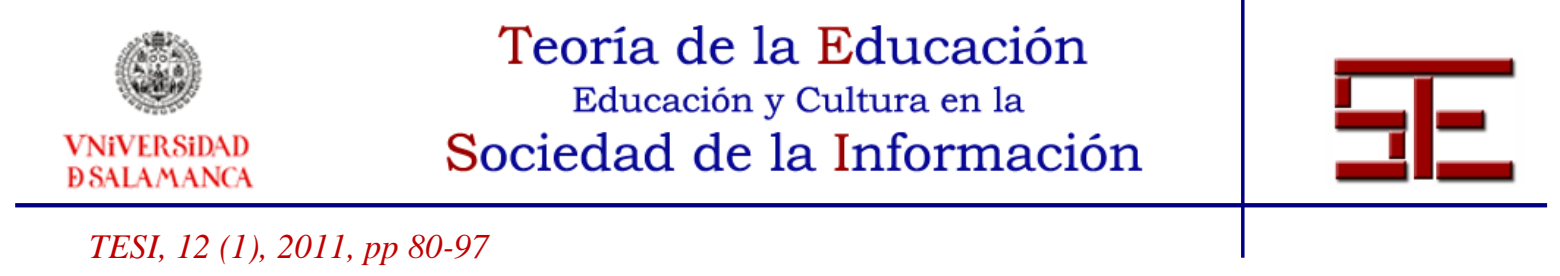

Para citar el presente artículo puede utilizar la siguiente referencia:

Leguízamo León, V. y García Carrasco J. (2011). Semántica de las búsquedas de información en entornos virtuales de formación, en Hernández Serrano, M. J. y Fuentes Agustí, M. (Coords.) La red como recurso de información en educación. Revista Teoría de la Educación: Educación y Cultura en la Sociedad de la Información. Vol. 12, $\mathrm{n}^{\circ}$ 1. Universidad de Salamanca, pp. 80-97 [Fecha de consulta: dd/mm/aaaa].

http://campus.usal.es/ revistas_trabajo/index.php/revistatesi/article/view/7824/7851

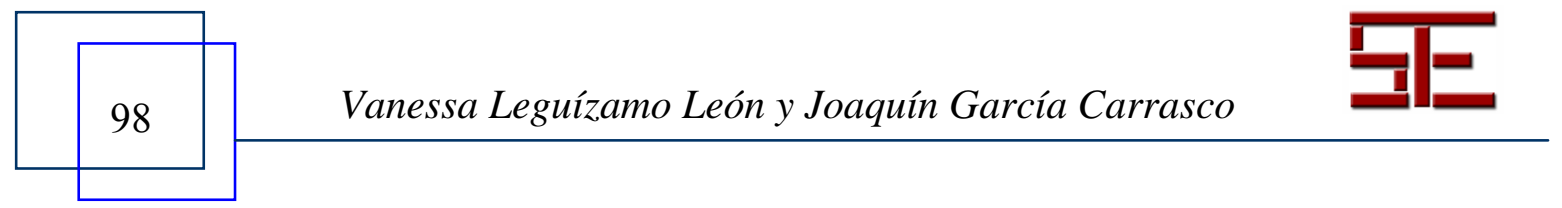

